FINAL REPORT

PROJECT NO. IS-3000-98

Regulation of L.H Secretion in the Periovulatory Period as a Strategy to Enhance Ovarian Function and Fertility in Dairy and Beef Cows

D. Wolfenson, W.W. Thatcher, J.E. Kinder 


\section{BARD Final Scientific Report \\ Cover Page}

Date of Submission of the report: December 2003

BARU Project Number: IS 3000 98R

Project Title: Regulation of LH secretion in the periovulatory period as a strategy to eniliance ovarian function and fertility in dairy and beef cows

Investiggtaxs

Institutions

Prineipal Investigator (PI): Davld Wolfenson, The Hebrew University

Co-Principal Investigators (Co PIs): Willian W. Thateher, Untversity of Florida James E. Kinder, Obio State University

Colaborating Investigatory: Rina Meidan, The Hebrew Univarsity

Keywords not appearing in the title and in order of importance. Avoid abbreviatiotis. Reproduction, Corpus luterm, Follicles, Progesterone, LH surge, Luteinization Abbreviatlons commonly used in the report, in alphabetical order: CL - corpus luterim

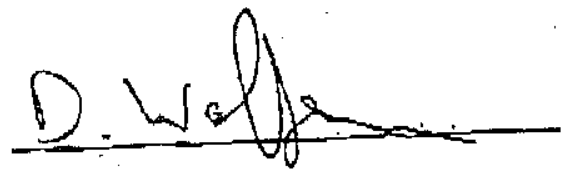

Signature

Principal Investigator

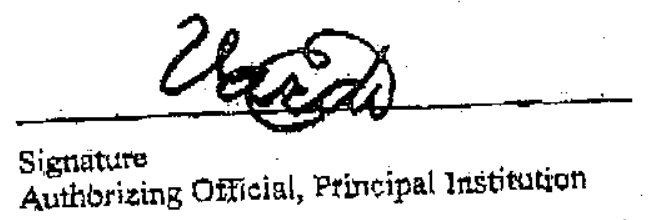

Authorizing Ofticial, Principal Institution 


\section{BARD Final Scientific Report \\ Cover Page}

Publication Summary (numbers)

\begin{tabular}{|l|l|l|l|l|}
\hline & $\begin{array}{c}\text { Joint } \\
\text { IS/US } \\
\text { authorship }\end{array}$ & $\begin{array}{c}\text { US Authors } \\
\text { only }\end{array}$ & $\begin{array}{c}\text { Israeli } \\
\text { Authors } \\
\text { only }\end{array}$ & \multicolumn{1}{|c|}{ Total } \\
\hline Refereed (published, in press, accepted) & & 10 & 4 & 14 \\
\hline Submitted, in review, in preparation & & & & \\
\hline Invited review papers & & 3 & & 3 \\
\hline Book chapters & & 2 & & 2 \\
\hline Books & & & & \\
\hline Master theses & & 1 & 3 & 4 \\
\hline Ph.D. theses & & 2 & & 2 \\
\hline Abstracts & & 14 & 5 & 19 \\
\hline Not refereed (proceedings, reports, etc.) & & 5 & 5 & 10 \\
\hline
\end{tabular}

Postdoctoral Training: List the names and social security/identity numbers of all postdocs who received more than $50 \%$ of their funding by the grant.

None

Cooperation Summary (numbers)

\begin{tabular}{|l|l|l|l|l|}
\hline & $\begin{array}{c}\text { From US to } \\
\text { Israel }\end{array}$ & $\begin{array}{l}\text { From Israel } \\
\text { to US }\end{array}$ & $\begin{array}{c}\text { Together, } \\
\text { elsewhere }\end{array}$ & Total \\
\hline $\begin{array}{l}\text { Short Visits \& } \\
\text { Meetings }\end{array}$ & & 2 & 3 & 5 \\
\hline $\begin{array}{l}\text { Longer Visits } \\
\text { (Sabbaticals) }\end{array}$ & & & & \\
\hline
\end{tabular}

\section{Description of Cooperation:}

Design of experiments, interpretation of data, application of results to next experiment. Assistance in preparation of manuscripts.

Patent Summary (numbers)

\begin{tabular}{|l|c|c|c|c|}
\hline & $\begin{array}{c}\text { Israeli inventor (s) } \\
\text { only }\end{array}$ & $\begin{array}{c}\text { US inventor (s) } \\
\text { only }\end{array}$ & $\begin{array}{c}\text { Joint } \\
\text { IS/US inventors }\end{array}$ & Total \\
\hline Submitted & & & & 0 \\
\hline Issued (allowed) & & & & 0 \\
\hline Licensed & & & & 0 \\
\hline
\end{tabular}




\title{
ABSTRACT \\ BARD Grant No. IS-3000-98R \\ Regulation of LH secretion in the periovulatory period as a strategy to enhance ovarian function and fertility in dairy and beef cows
}

\author{
David Wolfenson (IL), William W. Thatcher (FL), James E. Kinder (OH) and Rina \\ Meidan (W)
}

The general research objective was to increase herd pregnancy rates by enhancing corpus luteum (CL) function and optimizing follicle development, in order to increase conception rate and embryo survival. The specific objectives were: to determine the effect of the duration of the preovulatory $\mathrm{LH}$ surge on CL function; to determine the function of $\mathrm{LH}$ during the postovulatory period on $\mathrm{CL}$ development; to optimize $\mathrm{CL}$ differentiation and follicle development by means of a biodegradable $\mathrm{GnRH}$ implant; to test whether optimization of CL development and follicle dynamics in timedinsemination protocols would improve fertility in high-yielding dairy cows.

Low fertility in cattle results in losses of hundreds of millions of dollars in the USA and Israel. Two major causes of low fertility are formation of a functionally impaired CL, and subsequent enhanced ovarian follicle development. A functionally impaired CL may result from suboptimal LH secretion. The two major causes of low fertility in dairy cattle in US and Israel are negative energy status and summer heat stress; in both situations, low fertility is associated with reductions in LH secretion and impaired development of the ovulatory follicle and of the CL.

In Florida, the use of 450- $\mu \mathrm{g}$ deslorelin ( $\mathrm{GnRH}$ analogue) implants to induce ovulation, under the Ovsynch protocol resulted in a higher pregnancy rates than use of 750- $\mu \mathrm{g}$ implants, and pregnancy losses tended to decrease compared to controls, due probably to decrease in follicular development and estradiol secretion at the time of conceptus signaling to maintain the $\mathrm{CL}$. An alternative strategy to enhance progesterone concentrations involved induction of an accessory CL by injection of hCG on day 5 after the cows were inseminated. Treatment with hCG resulted in $86 \%$ of the cows having two CLs, compared with $23 \%$ of the control cows. Conception rates were higher among the hCG-treated cows than among the controls. Another approach was to replace the second injection of $\mathrm{GnRH}$ analogue, in a timed-insemination protocol, with estradiol cypionate (ECP) injected $24 \mathrm{~h}$ after the injection of $\mathrm{PGF}_{2 \alpha}$. Pregnancy rates were comparable with those obtained under the regular Ovsynch (timed AI) program. Use of ECP induced estrus, and cows inseminated at detected estrus are indeed more fertile than those not in estrus at the time of insemination. Collectively, the BARD-supported programs at the University of Florida have improved timed insemination programs.

In Ohio, the importance of the frequency of $\mathrm{LH}$ episodes during the early stages of the estrous cycle of cattle, when the corpus luteum is developing, was studied in an in vivo experiment in which cows were subjected to various episodic exposures to exogenous bovine $\mathrm{LH}$. Results indicate that the frequent $\mathrm{LH}$ episodes immediately following the time of ovulation are important in development of the corpus luteum, from the points of 
view of both size and functionality. In another study, rates of cell proliferation and numbers of endothelial cells were examined in vitro in CLs collected from cows that received post-ovulation pulsatile $\mathrm{LH}$ treatment at various frequencies. The results indicate that the corpora lutea growth that results from luteal cell proliferation is enhanced by the episodes of LH release that occur immediately after the time of ovulation in cattle. The results also show that luteal endothelial cell numbers did not differ among cows treated with different LH doses.

In Israel, a longer duration of the preovulatory LH surge stimulated the steroidogenic capacity of granulosa-derived luteal cells, and might, thereby, contribute to a higher progesterone output from the bovine corpus luteum. In an in vivo study, a subgroup of high-yielding dairy cows with extended estrus to ovulation interval was identified. Associated with this extended interval were: low plasma progesterone and estradiol concentrations and a low preovulatory $\mathrm{LH}$ surge prior to ovulation, as well as low postovulation progesterone concentration. In experiments based on the above results, we found that injection of $\mathrm{GnRH}$ at the onset of estrus increased the $\mathrm{LH}$ peak, prevented late ovulation, decreased the variability between cows and elicited high and uniform progesterone levels after ovulation. GnRH at estrus onset increased conception rates, especially in the summer, and among primiparous cows and those with low body condition. Another study compared ovarian functions in multiparous lactating cows with those in nulliparous non-lactating heifers. The results revealed differences in ovarian follicular dynamics, and in plasma concentrations of steroids and gonadotropins that may account for the differences in fertility between heifers and cows. 


\section{ACHIEVEMENTS}

\section{BARD Grant No. IS-3000-98R}

\section{Contribution of University of Florida}

To meet the overall grant objectives, the University of Florida completed a series of experiments centered on regulating LH-like actions, in order to enhance fertility. The overall impacts of these efforts were described in three symposia $(1,5,9)$. The first concerned the ability of a deslorelin implant via regulation of $\mathrm{LH}$ and $\mathrm{FSH}$ secretion to induce ovulation and to affect downstream follicular development and CL function that could enhance embryo survival. The second concerned the development of a timed insemination program that achieves normal fertility through reliance on estradiol induction of a spontaneous preovulatory LH surge with the use of Estradiol Cypionate. The third concerned augmentation of luteal phase progesterone concentrations and of the subsequent pregnancy rate by injection of hCG to induce ovulation of a day (d) 5 dominant follicle to form an accessory CL.

In the course of an Ovsynch-timed insemination program, final induction of ovulation with either 450,750 or $1000 \mu \mathrm{g}$ deslorelin (GnRH agonist) implant (i.e., biodegradable) resulted in formation of a normal $\mathrm{CL}$ with some evidence that this $\mathrm{CL}$ may be slightly more functional (i.e., not a consistent stimulatory response) than a CL induced by a standard GnRH injection (7). A subsequent attenuation in follicle development (i.e., both class 2 and 3 follicles) that continued through day 22 after treatment was detected repeatedly. A fertility trial evaluated the influence of deslorelin $(450$ or $750 \mu \mathrm{g}$ ) implants, when used to induce ovulation under the Ovsynch protocol, on pregnancy rates, embryonic loss and ovarian function in 593 lactating dairy cows (8). On day 27 after insemination, pregnancy rates were higher in the controls (39\%) and in the animals that received deslorelin $450 \mu \mathrm{g}$ implant $(41.3 \%$ ) than in those with the $750 \mu \mathrm{g}$ implant (27.5\%). Furthermore, pregnancy losses tended to be less among the $450 \mu \mathrm{g}$ deslorelin implant group (5\% vs $12.7 \%$ ) than among the controls. We attribute this increase in reproductive efficiency to the decrease in follicular development and estradiol secretion at the time of conceptus signaling to maintain the CL. In cows that did not conceive at first service, the pregnancy rate was decreased at the second re-synchronized service, because of continued suppression of follicular development. Evaluation of lower deslorelin implant doses is necessary to minimize the negative effects on subsequent fertility. The ability of a deslorelin implant $(2100 \mathrm{ug})$ to suppress postpartum ovarian activity, and so to prevent early ovulations that might compromise uterine health was demonstrated (2).

An alternative strategy to enhance progesterone concentrations involved induction of an accessory CL by injection of hCG (3,300 IU) on day 5 after cows were inseminated to a detected estrus (3). In 406 cows, treatment with hCG resulted in $86 \%$ of the cows having two CLs, compared with $23 \%$ of control cows. Conception rates were 
higher among hCG-treated than among control cows on days 28 (45.8\% vs $38.7 \%), 45$ $(40.4 \%$ vs $36.3 \%)$, and 90 (38.4\% vs $31.9 \%)$ after insemination. Treatment with hCG improved the conception rate in cows that lost body condition between insemination and day 28 after insemination. Lactating dairy cows have a lower occurrence of detected heats and lower estradiol concentrations during the proestrus period.

Two experiments were conducted in lactating dairy cows that underwent a synchronization protocol consisting of an injection of $\mathrm{GnRH}$ followed by $\mathrm{PGF}_{2 \alpha} 7$ days later with estradiol cypionate (ECP; $1 \mathrm{mg}$ ) injected $24 \mathrm{~h}$ after injection of $\mathrm{PGF}_{2 \alpha}$ (4). Ovulation occurred at about $55 \mathrm{~h}$ after injection of ECP. In two field trials in which cows received timed insemination at $48 \mathrm{~h}$ after ECP injection, pregnancy rates were comparable with those in an Ovsynch program. The ECP program has been defined as a Heatsynch protocol because of the induction of estrus, and cows inseminated at detected estrus are indeed more fertile than those not in estrus at the time of insemination. The program is well received by producers because cows have enhanced estrus tone at insemination. Cows in lower body condition appear to be less fertile under the Heatsynch program than under Ovsynch which may reflect a lower sensitivity of anestrus cows to release $\mathrm{LH}$ in response to ECP compared to direct stimulation of $\mathrm{LH}$ by GnRH of the Ovsynch program.

GnRH technology has been extended to resynchronization (6) with an injection of $\mathrm{GnRH}$ at day 21 after insemination and non-pregnant cows (i.e., those diagnosed by ultrasound at day 28) undergoing completion of the Ovsynch program (i.e., PGF $_{2 \alpha}$ on day $28, \mathrm{GnRH}$ on day 30 and TAl on day 31). Pregnancy rates and pregnancy losses following first inseminations and second re-synchronized inseminations were not altered by the resynchronization treatments that began at day 21 after the first insemination. The BARD-USDA-supported programs at the University of Florida have improved timed insemination programs and extended reproductive management systems into the area of re-synchronization. These approaches complement the concurrent programs in Israel and Nebraska.

\section{Contribution of Ohio State University}

The achievements of the research conducted at the Ohio State University (OSU) were consistent with the objectives presented in the submitted proposal. There were, therefore, no significant changes in research direction from the time of proposal submission until the time of completion of the Ohio component of the research endeavors. Specifically, the primary achievements of the research group at OSU that resulted from the funding of the BARD project was the elucidation of the importance of episodic luteinizing hormone (LH) pulses during the early period of corpus luteum development in cattle. These LH pulses stimulate cell proliferation and thus contribute to the development of luteal tissue; they may impact luteal function, as exhibited in the concentration of progesterone in the blood, through stimulation of the development of the luteal structure which, in turn, could ultimately enhance progesterone production by the corpus luteum. Luteal function in those animals is enhanced with frequent episodic LH stimulation of luteal tissues during the early developmental stages of the luteal structure. 
This enhanced function is most likely the consequence of stimulatory actions of the episodic LH pulses on luteal cell proliferation during the developmental stages of the corpus luteum. The research that was supported by the awarded funding has been published in abstract and thesis form. There will subsequently be peer-reviewed manuscripts that will be developed for publication in scientific journals. Appropriate recognition of BARD support will be indicated in those publications that result from this support.

Experiment 1. Experiment 1 was an in vivo investigation of the importance of episodes of luteinizing hormone $(\mathrm{LH})$ release during the early stages of the estrous cycle of cattle, when the corpus luteum is developing. The objective of the initial experiment was to determine the importance for corpus luteum development, of the episodic LH pulses that occur at 1- to 2-hour intervals during the early portion of the luteal phase of the estrous cycle. To achieve this goal, endogenous LH pulses were inhibited by administering a large dose of synthetic progestin, which completely blocks the release of LH pulses from the anterior pituitary during the initial 80 hours after ovulation. This period corresponds with the period when the tissues of the dominant follicle from which ovulation occurred are being transformed into luteal tissues. The positive control comprised those animals in which endogenous episodes of $\mathrm{LH}$ were not blocked (LH pulses in these animals typically occur at 1- to 2-hour intervals). The negative control comprised animals that had been treated with the large dose of synthetic progestin and not administered any LH via the exogenous route. The two treatment groups were administered purified bovine LH at intervals of 2 hours (typical of the corpus luteum development stages) or of 8 hours (typical of the mid-luteal phase after corpus luteum development). The size of the corpus luteum was assessed by real-time ultrasonography. The amount of progesterone produced by the corpus luteum during the estrous cycle in which treatments were administered was evaluated by measuring the concentration of progesterone in the blood during the same cycle.

The copora lutea were smaller $(P \leq 0.05)$ in the progestin-treated cattle that did not receive exogenous $\mathrm{LH}$ than in those of the control group in which the corpora lutea were stimulated by endogenous episodes of $\mathrm{LH}$ release. Concentrations of progesterone during the luteal phase of the estrous cycle in cattle that were not treated with synthetic progestin to block endogenous episodes of $\mathrm{LH}$ release were greater as compared with concentrations of progesterone in cattle in the three treatment groups in which endogenous LH pulses were blocked by progestin treatment regardless of whether the episodes of $\mathrm{LH}$ resulted from treatment with $\mathrm{LH}$. Concentrations of progesterone on days 8 through 10 of the estrous cycle (day 0 was the day on which behavioral estrus was detected) were greater $(P \leq 0.05)$ in cattle treated with episodes of $\mathrm{LH}$ at 2-hour intervals than in those treated with $\mathrm{LH}$ at 8-hour intervals and in those that were treated with progestin to block endogenous LH and not administered LH (negative control). The results of this research indicate that the frequent episodes of $\mathrm{LH}$ immediately following the time of ovulation are important in development of the corpus luteum, from the points of view of both size and function. The frequency of this episodic LH stimulation and the amount of LH stimulation that is necessary for development of a fully functional corpus luteum cannot be determined from the results of the present study. 
Experiment 2. Experiment 2 involved a logical sequence of in vitro focused investigation of the role of the episodic LH releases during the early stages of the estrous cycle, when the corpus luteum is forming, in the development of the important cells that contribute to the structure and function of the luteal tissue. As in Experiment 1, the frequency of episodes of LH release was controlled by treatment with a large dose of synthetic progestin that inhibits endogenous $\mathrm{LH}$ release episodes. The treatments were similar to those applied during Experiment 1, with the positive control group not receiving synthetic progestin so that a typical pattern of $\mathrm{LH}$ release episodes was followed (typically an episode every 1-2 hours). The negative control was treated with doses of synthetic progestin sufficiently large to completely inhibit endogenous episodes of $\mathrm{LH}$ release from the anterior pituitary. The two treatment groups received episodic doses of exogenous LH at 1.5- or 6-hour intervals from 24 until 96 hours after the onset of estrus, corresponding to times immediately preceding ovulation and during the early stages of luteal development after ovulation. Corpora lutea were collected on day 4 of the estrous cycle (day $0=$ day of detection of behavioral estrus). Specific histological markers were used to evaluate the cell proliferation rate (PCNA) and the numbers of endothelial cells (lectin). The PCNA staining index was greater $(P \leq 0.05)$ in cows with episodes of LH occurring at 6-hour intervals as a result of administration of LH, that did not differ from that of the positive control animals in which endogenous LH pulses were not inhibited and those of cows receiving exogenous LH at 1.5 hour intervals. This cell proliferation index was greater $(P \leq 0.05)$ in cows with episodes of $\mathrm{LH}$ at 6 -hour intervals and in those whose endogenous episodes of LH were not inhibited, than in those whose endogenous $\mathrm{LH}$ episodes were inhibited and did not receive episodic exogenous doses of LH (negative control). Endothelial cell numbers did not differ among cows in the four treatment groups as indicated by similar lectin staining indices for the corpora lutea from the cattle in the four groups. The results of this experiment indicate that corpora lutea growth that results from cell proliferation is enhanced by the episodes of $\mathrm{LH}$ release that occur around the time of ovulation in cattle.

\section{Experiment 3. Additional OSU Contribution to Area of Research Focus of BARD Grant Related to Florida Component on Grant (Funded by Appropriated funds from the State of Nebraska)} (Modified Abstract of Publication in Biology of Reproduction 69:398-403, 2003)

Our hypothesis in the present experiment was that administration of an agonist of gonadotropin releasing hormone $(\mathrm{GnRH})$ to cattle in which the $\mathrm{CL}$ was developing would enhance luteal function, as determined by plasma progesterone concentrations, and increase CL size, compared with those in cattle that received the agonist when the CL was fully functional. Cattle were chronically administered a GnRH agonist, azaglynafarelin, during days 3-21 (D3) or days 12-21 (D12), or served as untreated control females (day $0=$ behavioral estrus). Blood samples were serially collected on days 7 and 14 to evaluate $\mathrm{LH}$ release patterns, and twice daily to measure the plasma progesterone concentration. Ultrasonographic examinations were conducted daily to record the area of the CL. Corpus luteum size and plasma progesterone concentrations were both enhanced in the D3 group as compared with the control group. Progesterone concentrations on days 16 and 17 were greater in the D12 group than in the controls. Treatment with GnRH 
agonist increased the basal and mean LH concentrations in both D3 and D12 groups, as compared with the controls. We reject our working hypothesis, because we found that chronic administration of a GnRH agonist when the CL was developing and fully functional increased the plasma progesterone. The enhancement of the luteal function was most probably due to increased basal LH concentration.

\section{Contribution of The Hebrew University}

Experiment 1. In an in vitro setting, we examined the effects of short or long exposures of granulosa and thecal cells to various concentrations of $\mathrm{LH}$, on the steroidogenic capacity during 8 days of luteinization. On day 0 of culture granulosa and thecal cells were exposed to a range of LH concentrations for 4 or 12 hours. A significant effect of the duration of the LH treatment was observed in the luteinized granulosa cells: cells that were exposed to a long 'surge' produced more progesterone than those exposed to the shorter LH 'surge'. A non-significant trend indicated that the subsequent enhancement in progesterone production over that in the low-amplitude 'surge' treatments was greater following the long-duration, high-amplitude LH treatments than following the short-duration, high-amplitude treatments. This finding has important physiological significance, because large luteal cells account for most of the progesterone secreted by the corpus luteum. No differences in progesterone production were observed among luteinized thecal cells exposed to the various durations or amplitudes of $\mathrm{LH}$ 'surges'. These results suggest that a longer duration (and higher amplitude) of the preovulatory $\mathrm{LH}$ surge stimulates the steroidogenic capacity of granulosa-derived luteal cells, and might thereby contribute to enhanced progesterone output from the bovine corpus luteum.

Experiment 2. The short fertile lives of the male and female gametes in the female tract necessitates accurate timing of insemination. We examined the effects of season, parity, milk yield, body condition, and concentrations of steroids and LH surge prior to estrus, on the intervals between estrus and ovulation, estrus and LH surge, and LH surge and ovulation, and on post-ovulation progesterone curves. The data show a subgroup of about $12 \%$ of the cows with an extended interval between estrus and ovulation, that was associated with low plasma progesterone and estradiol concentrations and low preovulatory LH surge prior to ovulation, and with low post-ovulation progesterone concentration. It may result in non-optimal timing of insemination, which would lower the fertilization rate and lead to low fertility. In light of the above results, we conducted another experiment in which we injected GnRH at the onset of estrus, and found that it increased the LH peak, prevented late ovulation, decreased the variability between cows and elicited high and uniform progesterone levels after ovulation. It seems that treatment with GnRH increased progesterone concentrations in cows with a long interval between estrus and ovulation, that exhibited low post-ovulation plasma progesterone concentrations. GnRH treatment at estrus onset might improve the fertility of the subgroup with delayed ovulation and low progesterone levels.

Experiment 3. In light of the results obtained in Experiment 2, we conducted another BARD-related fertility study in which we injected GnRH analogue at onset of 
estrus. GnRH increased the conception rates in the summer, but not in the winter, from 35.1 to $51.6 \%$. In both seasons GnRH increased the conception rates of cows with a low body condition score at AI from 36.0 to $61.5 \%$. GnRH increased the conception rate of primiparous cows compared with that of the controls (63.2 vs. $42.2 \%$ ); the effect was less in multiparous cows.

Experiment 4. We examined differences in follicular development and circulating hormone concentrations, between lactating cows and nulliparous heifers; these differences may relate to differences in fertility between the groups. Multiparous, cyclic, lactating Holstein cows and cyclic heifers were examined in the winter, during one estrous cycle. We found that the ovulatory follicle was smaller in heifers than in cows. The greater numbers of large follicles in cows than in heifers corresponded well to the higher concentrations of FSH in cows. Estradiol concentrations around estrus, and the preovulatory LH surge were higher in heifers than in cows. The higher progesterone concentrations in heifers than in cows during the luteal phase corresponded well to the higher preovulatory $\mathrm{LH}$ surge. The duration of dominance of the ovulatory follicle tended to be longer in cows than in heifers. The results revealed differences in ovarian follicular dynamics, and in plasma concentrations of steroids and gonadotropins; these may account for the differences in fertility between nulliparous heifers and multiparous lactating cows.

In conclusion, the major achievements of the experiments conducted in Israel are the following findings: shorter duration and lower amplitude of the LH surge at the beginning of culture is associated with lower progesterone production by luteinized granulosa cells; a subgroup of high-yielding dairy cows exhibited an extended interval between estrus and ovulation, that was associated with low LH surge and low plasma progesterone; GnRH administration at the onset of estrus decreased the variability among cows in their estrus-to-ovulation interval, and increased the preovulatory LH surge and luteal progesterone concentration; $\mathrm{GnRH}$ administration at the onset of estrus improved fertility of dairy cows, especially in the summer, and in nulliparous cows and those with low body condition; heifers, known to have higher conception rates than lactating cows, exhibited a higher preovulatory estradiol concentration and a larger $\mathrm{LH}$ surge, that could be associated with a higher post-ovulatory progesterone concentrations. Taken together, the pattern of the preovulatory LH surge could be related to the fertility potential of the dairy cow. 


\section{PUBLICATIONS RESULTING FROM THIS BARD PROJECT}

\section{Florida Publications}

1. Thatcher, W.W., F. Moreira, J.E.P. Santos, R.C. Mattos, F.L. Lopes, S.M. Pancarci and C.A. Risco. 2001. Effects of hormonal treatments on reproductive performance and embryo production. Theriogenology 55: 75-89, 2001.

2. Mattos, R., C. Orlandi, J. Williams, C.R. Staples, T. Trigg and W.W. Thatcher. 2001. Effect of an implant containing the GnRH agonist Deslorelin on secretion of LH, ovarian activity and milk yield of postpartum dairy cows. Theriogenology: 56: 371-386.

3. Santos, J.E.P., W.W. Thatcher, L. Pool and M.W. Overton. 2001. Effect of human chorionic gonadotropin on luteal function and reproductive performance of highproducing lactating Holstein dairy cows. J. Anim. Sci. 79: 2881-2894.

4. Pancarci, S.M., E.R. Jordan, C.A. Risco, M.J. Schouten, F.L. Lopes, F. Moreira and W.W. Thatcher. 2002. Use of estradiol cypionate in a pre-synchronized timed artificial insemination program for lactating dairy cattle. J Dairy Sci. 85: 122-131.

5. Thatcher, W.W., F. Moreira, S.M. Pancarci, J.A. Bartolome and J.E.P. Santos. 2002. Strategies to optimize reproductive efficiency by regulation of ovarian function. Domest. Anim. Endocrinol. 23: 243-254.

6. Chebel R.C., J.E.P. Santos, R.L.A. Cerri, K.N. Galvao, S.O. Juchem and W.W. Thatcher. 2003. Effect of resynchronization with $\mathrm{GnRH}$ on day 21 after artificial insemination on pregnancy rate and pregnancy loss in lactating dairy cows. Theriogenology 60: 1389-1399.

7. Bartolome, J.A., J.E.P. Santos, S.M. Pancarci, P. Melendez, A.C.M. Arteche, O. Hernandez, L.F. Archbald, T. Trigg, W.W. Thatcher. 2004. Induction of ovulation in nonlactating dairy cows and heifers using different doses of a delorelin implant. Theriogenology 61: 407-419.

8. Santos, J.E.P., J.A. Bartolome, R.L.A., Cerri, S.O. Juchem, O. Hernandez, T. Trigg, W.W. Thatcher. 2004. Effect of a deslorelin implant in a timed artificial insemination protocol on follicle development, luteal function and reproductive performance of lactating dairy cows. Theriogenology 61: 421-435.

\section{ADDITIONAL PUBLICATION FROM FLORIDA RELATED TO BARD PROJECT}

9. Thatcher, W.W, A. Guzeloglu, A. Meikle, S. Kamimura, T. Bilby, A.A. Kowalski, L. Badinga, R. Pershing, J. Bartolome, J.E.P. Santos. 2003. Regulation of embryo survival in cattle. In: Reproduction in Domestic Ruminants V, B.K. Campbell, R. Webb, H. Dobson and C. Doberska, editors. Reproduction Supplement 61, pp 253-266.

\section{Ohio Publications}

10. Clopton, D, A. Mohamed, T. Davis, H. Jimenez-Severiano, K. Pearson, and J. Kinder. 2000. Influence of luteinizing hormone $(\mathrm{LH})$ pulses after ovulation on cell population in the corpus luteum of cattle. Biol. Reprod. 62 (Suppl. 1): 141.

11. Davis, T, M. Mussard, H. Jimenez-Severiano, W. Enright, and J. Kinder. 2000. Enhanced luteal function in cattle chronically administered with gonadotropin 
releasing hormone (GnRH) agonist Azagly-Nafarelin. Biol. Reprod. (Suppl. 1): 211.

12. Mussard, M., 2000, Importance of episodic release of luteinizing hormone in development of corpora lutea in cattle. in: Thesis entitled Regulation of FSH Synthesis and Control of Ovarian Follicular Development in Beef Cattle. Master of Science Thesis. University of Nebraska.

\section{ADDITIONAL PUBLICATION FROM OHIO RELATED TO BARD}

\section{PROJECT}

13. Davis, T.L., M.L. Mussard, H. Jimenez-Severiano, W.J. Enright, and J.E. Kinder. 2003. Chronic treatment with an agonist of gonadotropin-releasing hormone enhances luteal function in cattle. Biol. Reprod. 69:398-403.

\section{Israel Publications}

14. Biger, E., D. Wolfenson, R. Mamluk, N. Levi, Y. Graber and R. Meidan. Effects of LH 'surge' patterns on the steroidogenic capacity of bovine follicular cells luteinized in vitro. $14^{\text {th }}$ Int. Cong. Anim. Reprod. Stockholm, Abst. 1:27, 2000.

15. Blöch, A., D. Wölfension, M: Kaim, Z. Roth; R: Braw-Tal and Y. Folman. Factors affecting the time intervals between estrus, LH surge and ovulation in high-yield dairy cows. The Joint Annual Meeting of the American Society of Animal Science, and American Dairy Science Associations, Indianapolis, J. Anim. Sci. 79 (Suppl. 1) $\Lambda$ bst. 1924, p. 464-5, 2001.

16. Wolfenson D., G. Inbar, Z. Roth, M. Kaim, A. Bloch, and R. Braw-Tal. Follicular dynamics and concentrations of steroids and gonadotropins in lactating cows and nulliparous heifers. Theriogenology, in press, 2004.

ADDITIONAL PUBLICATION FROM ISRAEL RELATED TO BARD PROJECT

17. Kaim, M., A. Bloch, D. Wolfenson, R. Braw-Tal, M. Rosenberg, H. Voet and Y. Folman. Effects of GnRH administered to cows at the onset of estrus on timing of ovulation, endocrine responses and conception rates. J. Dairy Sci., 86:2012-2021, 2003. 